\title{
Contribución empírica al debate teórico sobre el origen de la crisis capitalista desde distintas perspectivas
}

Segundo lugar en el concurso de tesis del Departamento de Economía de la UCA, en las Jornadas "Francisco Javier Ibisate", 2014

Francisco Gavidia, José Magaña, Karla Méndez, Beatriz Montenegro. Universidad Centroamericana "José Simeón Cañas"

\section{Resumen}

La realidad se desenvuelve en torno a procesos de conflictos, a partir de determinadas relaciones de poder sustentadas en las relaciones sociales de producción. Bajo este marco, en la construcción social se desarrolla un conflicto por la imposición ideológica, reflejado en los debates teóricos. El debate de las teorías económicas, en particular alrededor de las crisis en el capitalismo, adquiere fuertes implicaciones sociales, en tanto la teoría predominante brinda, o no, una conciencia de clase y dictamina la conducta de los sujetos colectivos. Este documento aporta un análisis empírico a este debate teórico, a fin de demostrar que las medidas adoptadas, más que basarse en un criterio técnico, son resultado del conflicto de clase y, por tanto, responden a los intereses de la clase que ejerce el poder, por encima de los de la sociedad como conjunto.

\section{Abstract}

The reality unfolds around conflict processes, based on certain power relations grounded in social relations of production. Under this framework, a conflict appears inside of social construction about the ideological imposition, reflected in the theoretical debates. The discussion of economic theories, especially around crises in capitalism, acquires strong social implications, as the prevailing theory provides, or not, class conscious and dictates the behavior of collective subjects. This paper provides an empirical analysis of this theoretical debate, to demonstrate that the measures adopted, rather than based on a technical judgment, are the result of class struggles and, therefore, respond to the interests of the class which holds the power, above those of society as a whole.

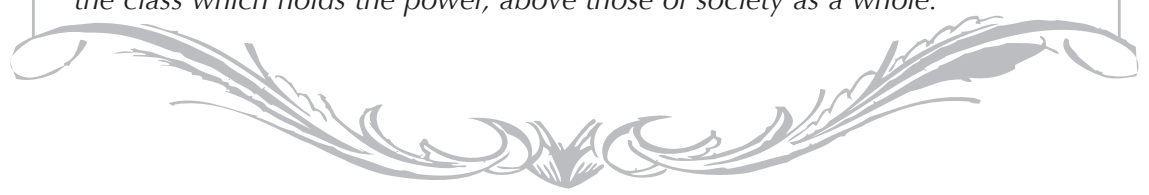


En los últimos años, a partir de la crisis actual, se le ha otorgado mayor relevancia a la investigación sobre los orígenes de las crisis del modo de producción capitalista. Esto ha llevado nuevamente a la palestra el debate entre las escuelas de pensamiento económico, así como al interior de las mismas.

Para el abordaje de la presente investigación, es preciso considerar que cada una de las teorías estudiadas se corresponde a una determinada forma de acercamiento a la realidad. De modo que, las categorías utilizadas y las dinámicas planteadas están cargadas de contenido ideológico, esto es, de las formas de la conciencia social que responden a una determinada estructura económica. Por tanto, más que una materialización de las ideas que buscan el estudio de tendencias naturales, las teorías son el reflejo de un proceso de producción de ideas bajo determinadas condiciones históricas y, por tanto, responden a determinadas estructuras sociales.

Cada teoría sistematiza las ideas que explican cómo y porqué suceden las crisis en el capitalismo, por tanto, de la que adquiera predominancia emanarán las medidas que han de aplicarse para enfrentar o contrarrestar las crisis. Sin embargo, la predominancia de una teoría obedece a los objetivos reales que persigue y la eficacia de dichas medidas dependerá del nivel en el que la teoría se corresponde con la realidad.

De lo anterior se deriva la importancia de conocer las diferentes explicaciones que han cobrado más protagonismo en el debate. Es a través de una contrastación de las distintas teorías con la realidad, teniendo en cuenta las implicaciones políticas, sociales y económicas que cada una conlleva, que es posible estructurar una visión crítica sobre si la primacía de una determinada teoría está justificada, o si esta no hace más que esconder intereses particulares específicos. Es esta la razón por la que es fundamental el estudio de este debate.

La revolución keynesiana, a partir de la crisis de 1929, inició una fase de regulaciones y de intervención estatal en la estructura productiva y social de los países. A partir de la década de 1970, cobran fuerza las políticas inspiradas en el desarrollo teórico del monetarismo, sobre el cual se encuentra construida la mayor parte de la estructura de las instituciones económicas actuales.

Si bien las consecuencias de la crisis plantean un cuestionamiento a los postulados monetaristas, las propuestas y medidas adoptadas mantienen su esencia teórica. 
Existen, sin embargo, análisis críticos hacia estas tendencias, pero sin abandonar el esquema del modo de producción capitalista, desde corrientes inspiradas en el desarrollo teórico keynesiano. Es fundamental, además, considerar en el debate, propuestas teóricas que abordan el tema desde una perspectiva que permita cuestionar la estructura económica, a través del análisis de las relaciones sociales de producción y sus contradicciones; esta temática es desarrollada por la teoría marxista.

En el primer apartado, se exponen los fundamentos teóricos planteados por las escuelas monetarista, keynesiana y marxista, que permiten entender los orígenes de las crisis capitalistas e identificar las implicaciones políticas y sociales que conllevan.

En el segundo apartado, se realiza una contrastación empírica a través de modelos econométricos, formulados con base en las variables expuestas como determinantes por las diferentes teorías. Esto, para comprobar el poder explicativo de cada una de ellas con respecto a la realidad.

En el tercer apartado, se evalúa si las medidas adoptadas por Estados Unidos y la Unión Europea para el manejo de la crisis actual, corresponden a los fundamentos teóricos que, de acuerdo con el capítulo dos, podrían explicar de mejor forma la realidad.

En el cuarto apartado, se concretizan las manifestaciones de la crisis para el caso de El Salvador, los mecanismos de transmisión y el trasfondo de las medidas adoptadas para el manejo de la crisis.

Finalmente, se presentan unas consideraciones finales a partir del análisis desarrollado en el transcurso de la investigación.

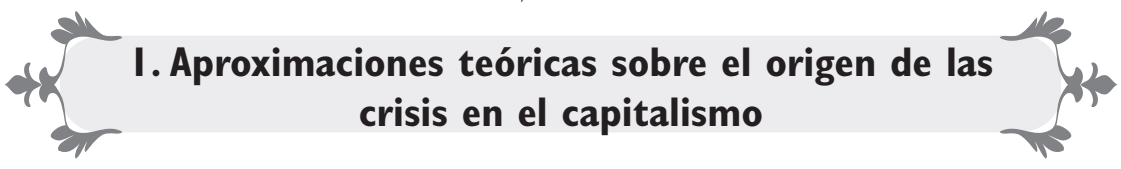

La figura 1.1 muestra, de manera esquemática, las escuelas de pensamiento económico desarrolladas en el presente capítulo. A partir de estas, se realiza una sistematización metodológica que permite contrastar los planteamientos en torno a los orígenes de las crisis en el capitalismo. 


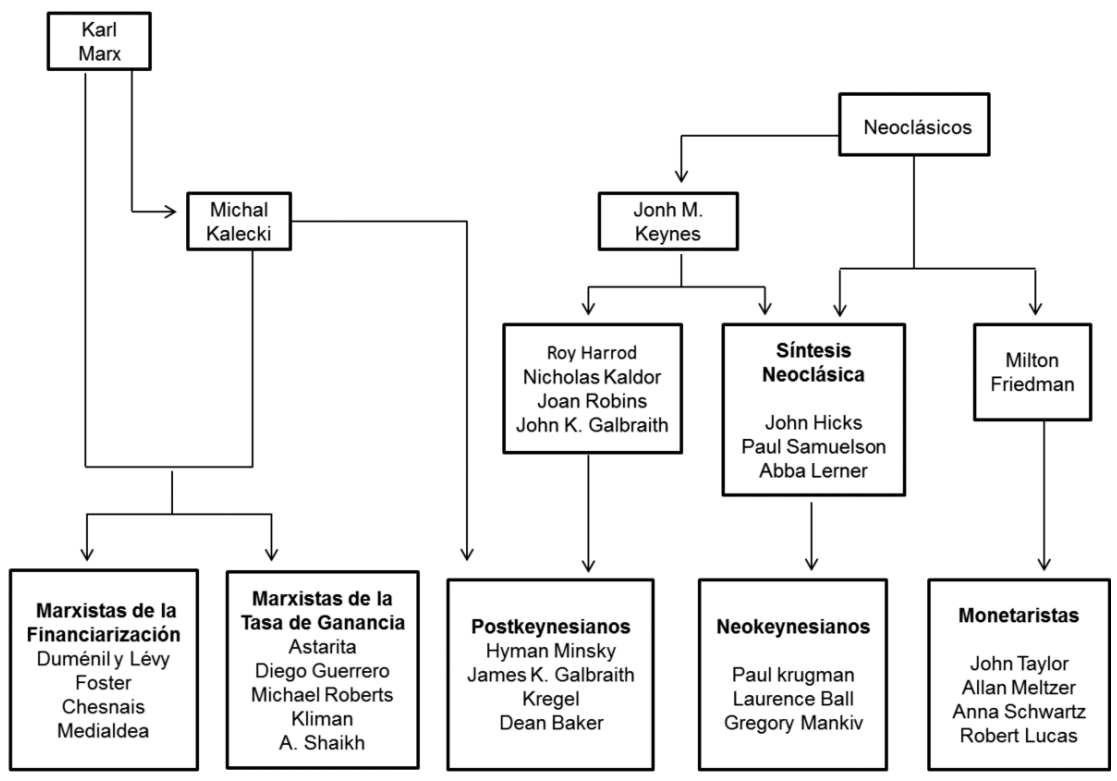

Fuente: Elaboración propia a partir de Lavoie (2005).

\subsection{La teoría de la crisis: enfoque monetarista}

Los monetaristas defienden la premisa de que la estabilidad es inherente a la economía de mercado. Proponen una intervención tecnocrática y no política, ya que esta última desarrolla un papel perjudicial y desestabilizador en la economía.

De acuerdo con Friedman:

La noción central del monetarismo es que la moneda incide sobre las fluctuaciones económicas a corto plazo de la economía y sobre la inflación, o sea la tendencia de los precios. Parte de la noción central, es que lo que importa es la cantidad de dinero y no las tasas de interés, las condiciones del mercado monetario, las condiciones de crédito, y cosas por el estilo (Friedman, 1979, p.2).

Por tanto, la política monetaria tiene una gran importancia, sobre todo tomando en cuenta el daño que, según autores monetaristas, puede causar si es implementada erróneamente. Así, de acuerdo con 
el monetarismo, las crisis son el resultado de malas gestiones/admi- nistraciones mediante intervenciones discrecionales o políticas partidistas:

Un enfoque de política monetaria sensato sería no cambiar la oferta monetaria de moneda de manera constante si no ajustándola de acuerdo a los cambios en la demanda de dinero (...) suponiendo que la demanda real de dinero es perfectamente estable y, por lo tanto, modificando la oferta nominal a una tasa estable, en lugar de tratar de hacer ajustes finos por los cambios de demanda real (Friedman, 1979, p. 34).

De lo contrario, se genera un exceso (escasez) de oferta de dinero, provocando procesos inflacionarios (deflacionarios). La inflación se considera un fenómeno monetario, reflejo de lo que ocurre en la cantidad de dinero por unidad de producción.

Por otro lado, para los monetaristas existe una relación constante, aunque no exacta, entre el índice de crecimiento de la cantidad de dinero y el índice de crecimiento de los ingresos nominales. De ahí que, si bien un desequilibrio de la demanda agregada desempeña un papel en la crisis, las causas las identifican con desequilibrios monetarios.

En cuanto a la política fiscal expansiva, se plantea que si el gasto o el déficit es financiado por aumentos en la oferta monetaria se generan procesos inflacionarios. Mientras, si es financiado por incrementos en la deuda se producen desplazamientos de cartera.
Con respecto al papel del Estado, Friedman (1979) plantea que cuanto más se limite a reglas simples, conocidas de antemano por los agentes económicos, la intervención será menos desestabilizadora. Además, propone como receta la adopción de la regla monetaria. Esto es, un crecimiento constante de la oferta monetaria basado en las proyecciones de crecimiento de largo plazo. A la vez, con el fin de lograr un equilibrio presupuestario, la fiscalidad y los gastos deben obedecer a reglas similares de estabilidad.

Friedman (1979) también plantea que no se puede disminuir el desempleo con inflación debido a la inexistente correspondencia entre las variables en el largo plazo. Para ello, es necesario reformar el mercado de trabajo para que éste sea más libre; así, se asegura un ajuste de salarios para disminuir el desempleo. A largo plazo, se considera que el nivel de producción y empleo tienden, por la fuerzas de 
la oferta y de la demanda, a sus niveles naturales.

Anna Schwartz (citada en Carney, 2008) plantea que la crisis actual no se enfrenta a un problema de escasez de liquidez, sino, a la falta de credibilidad en los balances de las compañías financieras, como resultado de un desequilibrio en el mercado del crédito, producto de malas decisiones por parte de las autoridades, lo que hace erróneas muchas de las medidas tomadas por la Reserva Federal (FED) (Banco Central de Estados Unidos).

Puntualmente, Schwartz atribuye las causas de la crisis a tres factores: la política monetaria expansiva, la adopción de innovaciones financieras y el colapso en el mercado de determinados instrumentos financieros.

Taylor (2009) señala como principal causa de la crisis la intervención pública, con una política monetaria excesivamente laxa de bajos tipos de interés, potenciando el auge del mercado inmobiliario.

Asimismo, Robert Lucas (citado en Martín, 2012) establece que el desplome del precio de las acciones en búsqueda de activos respaldados por el gobierno, derivó en la disminución del gasto en las empresas, lo que considera una de las principales causas de la recesión.

Para Meltzer (citado en Kurata, 2009), la causa de la crisis actual no es la falta de reglamentación financiera, sino que los bancos y las instituciones financieras aprendieron a evadirla: "La primera regla de la reglamentación es que los burócratas y los abogados redactan los reglamentos, mientras que los banqueros y los mercados aprenden a eludirlos".

La revisión de estos planteamientos permite concluir que, para los monetaristas, las causas de las crisis, en general, provienen de choques externos y de excesivo intervencionismo estatal sin correspondencia con criterios tecnocráticos. Por tal razón, las crisis son evitables en tanto son ajenas al funcionamiento mismo de la economía de mercado. De manera que proponen la desregulación de los mercados con base en las reglas claras y firmes que establece la teoría monetarista como principios que se deben cumplir para garantizar el correcto funcionamiento de la economía.

\subsection{La teoría de las crisis: enfoque keynesiano}

Los planteamientos keynesianos se desvinculan, en cierta medida, de los aportes de la teoría neoclásica y marcan un giro en el análisis del sistema económico en su totalidad. El aporte primordial de Keynes radica en dos ideas fundamentales: en primer lugar, la necesidad de intervención del Estado para estimular la demanda efectiva y salir del estancamiento; y en 
segundo lugar, la incapacidad de la economía capitalista para alcanzar, de manera natural y automática, el pleno empleo de los recursos (Gill, 2002, p.652). De manera que la economía de mercado es incapaz de alcanzar equilibrios por ajustes automáticos, por lo que se vuelve necesaria la intervención del Estado.

Desde la perspectiva keynesiana, las crisis en el sistema capitalista son originadas por una disminución en la demanda efectiva, lo que ocasiona el estancamiento y desempleo. De acuerdo con esta perspectiva, el aumento de la preferencia por la liquidez de los capitalistas, quienes prefieren conservar su dinero y no arriesgarse a invertirlo, genera un incremento en la tasa de interés, que luego se traduce en una disminución en la propensión a invertir. Sin embargo, para Keynes (1965), "la explicación más típica, y con frecuencia la predominante de la crisis, no es principalmente un alza en la tasa de interés, sino un colapso repentino de la eficiencia marginal del capital" (p. 281).

A partir de los planteamientos de Keynes, algunos autores buscaron armonizarlos con postulados de la teoría neoclásica, surgiendo así una corriente fundamentada en las ideas de Paul Samuelson, la cual es denominada neokeynesianismo.

De acuerdo con la opinión de algunos neokeynesianos, la crisis actual es una crisis financiera. Por tal razón, el origen de la misma deberá buscarse en la pérdida de confianza de los mercados financieros (Tapia, 2010, p.2). La perspectiva neokeynesiana reconoce que una disminución del crédito, combinado con esta pérdida de confianza, agudiza la salida de capitales en las instituciones financieras.

Por tanto, Krugman y Layard establecen que el origen de la crisis actual no radica en el endeudamiento público irresponsable. La crisis fue potenciada más bien por el excesivo endeudamiento del sector privado y el sobre-apalancamiento de los bancos. Los enormes déficits públicos no son una causa de la crisis actual, sino una consecuencia de la misma (Krugman y Layard, citado en Roberts, 2012).

Para hacerle frente al desarrollo de este keynesianismo bastardo, como Joan Robinson le llamaba (Schweickart, 1997 p.39, nota 8), surge el postkeynesianismo: Una corriente de pensamiento más fiel a los principios y postulados keynesianos tradicionales. Mantiene la ruptura con los planteamientos de la teoría neoclásica y se desliga en ciertos aspectos del neokeynesianismo.

Algunos economistas postkeynesianos, como Wray (2007) y Kregel (2008), clasifican la crisis económica actual como una crisis financiera o una crisis tipo 
Minsky. Esto es, una crisis donde la fragilidad e inestabilidad de los mercados financieros se encuentra ligada a los ciclos económicos (Girón y Chapoy, 2009 p.48). Ambos autores se fundamentan en la teoría de la fragilidad financiera de Hyman Minsky.

Ambas corrientes de esta escuela conciben las crisis como eventos evitables, y, más importante aún, gestionables. Al aplicar las políticas adecuadas se puede lograr que el capitalismo funcione 'correctamente'. Para ello, debe permitírsele al Estado participar activamente para garantizar los equilibrios a través de la regulación (de los 'espíritus salvajes' —como diría Keynes - de los capitalistas y los especuladores). Sin embargo, existe una diferencia fundamental entre las corrientes. Para los neokeynesianos, el papel del Estado está más vinculado a la regulación de los mercados, mientras que para los postkeynesianos, a la intervención.

\subsection{La teoría de las crisis: enfoque marxista}

Desde la perspectiva de las corrientes teóricas marxistas, se abordan planteamientos principalmente vinculados a dos fenómenos. El primer aspecto, más relacionado con la disociación intertemporal de la metamorfosis de la mercancía, se refiere al incremento del peso relativo adquirido por el sistema financiero en la economía. En segundo lugar, la tendencia decreciente de la tasa de ganancia reconocida como ley fundamental del capitalismo.

Los principales planteamientos de Marx sobre los orígenes de las crisis en el capitalismo se encuentran en su obra El capital. El objeto de estudio de la mencionada investigación "consiste en el análisis crítico de la esencia, legalidad y movimiento del modo de producción capitalista, comprendido como una estructura preñada de leyes y contradicciones tendenciales que apuntan hacia su muerte" (Montoya, 1998, p. 29).

De manera que la crisis, en el planteamiento de Marx, es una condición inherente y necesaria del modo de producción capitalista y su origen se encuentra en las contradicciones de su propio desarrollo, expresadas en la tasa de ganancia y la separación en el tiempo de la metamorfosis de la mercancía.

La racionalidad de los capitalistas de incrementar incesantemente sus ganancias, mediante la disminución de costos, conduce a tecnificar la producción con la incorporación de nuevos métodos y tecnologías (Astarita, 2009, p. 167).

Por tanto, se establece como ley general que el incremento progresivo del capital constante en proporción al variable, propio de la producción capitalista y de su desarrollo, tiene como consecuencia 
una caída de la tasa de ganancia, aún si el grado de explotación permanece invariable o incluso aunque aumente (Marx, 1973, p. 167).

Las contradicciones reflejadas en la tendencia decreciente de la tasa de ganancia implican también contradicciones a escala más interna. Según Marx, a medida que se desarrolla el capitalismo, paralelamente se desarrolla el crédito y todo el sistema financiero, ante lo que plantea que:

En un sistema de producción en que toda la trama del proceso de reproducción descansa sobre el crédito, cuando éste cesa repentinamente y sólo se admiten pagos al contado, tiene que producirse inmediatamente una crisis; una demanda violenta y en tropel de medios de pago. Por eso, a primera vista, la crisis aparece como una simple crisis de crédito y de dinero, mientras sólo se trata de la convertibilidad de las letras de cambio en dinero. (...) Al lado de esto, hay una masa inmensa de estas letras que sólo representan negocios de especulación, que ahora se ponen al desnudo y explotan como pompas de jabón. (Marx, 1973, p. 317).

Uno de los desarrollos teóricos al que mayor investigación se le ha dedicado desde corrientes marxistas, con autores como Chesnais, Foster, Duménil y Levy, ha sido la tesis de la financiarización.

Medialdea (2009, p. 119) entiende la financiarización como "un aumento de la importancia del capital financiero que se traduce en el creciente protagonismo económico y político de los agentes que lo representan y, por tanto, en el incremento de su capacidad para imponer sus intereses". De lo anterior, la autora plantea que en la configuración de una lógica financiarizada, los espacios de valorización del capital financiero se imponen al resto de la actividad y relaciones económicas.

Duménil y Lévy (2011) plantean que la crisis de la década de 1970 fue causada por el bajo nivel de la tasa de ganancia (una crisis à la Marx) después de la recuperación en las décadas de postguerra. Pero a partir de ese punto, las medidas adoptadas desde los modelos neoliberales de desregulación y liberalización permitieron una recuperación de la tasa de ganancia.

Para Foster (2010), la tendencia hacia la financiarización se refleja en particular en los siguientes aspectos: 
a. Aumento de la alícuota de beneficios financieros en los beneficios totales.

b. Creciente deuda respecto al Producto Interno Bruto (PIB).

c. Expansión de la participación de finanzas, seguros y bienes raíces en el ingreso nacional.

d. Proliferación de exóticos y poco transparentes instrumentos financieros.

e. La extensión del papel de las burbujas financieras.

Otro rasgo característico de la era de la financiarización, reconocido por los autores de esta línea, es el bajo nivel de acumulación - medido por la inversión- que se realiza en la economía. Duménil y Lévy (2011) plantean que la alta parte de los dividendos pagados en relación a los dividendos retenidos, provoca bajas tasas de acumulación, que se financian básicamente de los dividendos retenidos y no reflejan la dinámica de la tasa de ganancia. De manera que, el exceso de dividendos pagados se destina a alimentar la financiarización de la economía.

A pesar de la coincidencia en las características de la financiarización, existe también heterogeneidad en cuanto a la explicación de su origen.
Para Duménil y Lévy ha sido precisamente el marco institucional de desregulaciones y liberalizaciones del neoliberalismo lo que ha permitido la recuperación de la tasa de ganancia, pero llevando a desbordar el sector financiero.

Sin embargo, otros autores de la tesis de la financiarización, como Foster, afirman que "es más acertado ver en el neoliberalismo la expresión política de la respuesta del capital a la trampa del estancamiento-financiarización" (Foster, 2010, p. 12.); en tanto, es la financiarización de la acumulación la que ha dado fuerza a la implementación de políticas neoliberales.

Así, bajo la perspectiva de Duménil y Lévy, el neoliberalismo permitió la escalada del sector financiero en la economía. Mientras, para Foster, son las tendencias hacia la financiarización las que impulsan las medidas de desregulación y liberalización de mercados.

De esta manera, si se trata de una crisis del neoliberalismo, como sostienen Duménil y Lévy (2011), la propuesta es un compromiso entre los cuadros directivos y los sectores populares en el que se retome la reconstrucción del sector financiero, estabilización de la trayectoria de la economía y regulación al comercio internacional y movimiento de capitales. 
Mientras, si se aborda la crisis desde la perspectiva que la financiarización, como consecuencia del desarrollo del capitalismo, ha desembocado en desregulaciones y liberalizaciones, más allá que un cambio del modelo neoliberal, es necesario "reemplazar un sistema global totalmente entregado a la búsqueda del lucro monetario por la creación de una nueva sociedad orientada a lograr la igualdad sustantiva y un desarrollo humano sostenible" (Foster, 2010, p.13).

Algunos autores marxistas como Roberts, Guerrero, Astarita, Kliman y Shaikh, entre otros, son críticos de la tesis de la financiarización. Uno de los principales argumentos se fundamenta en la atención a la tasa de ganancia como causa subyacente de la crisis.

Roberts (2009, p. 41) plantea que, como lo pronosticó Marx, la tasa de ganancia promedio tiende a descender en el capitalismo, manteniendo una relación inversa con la composición orgánica. Además, afirma que el periodo actual es un ciclo de contracción de la tasa de ganancia, por lo que el capitalismo se encuentra en una era donde las crisis serán más frecuentes y severas, con mayores repercusiones políticas.

La visión cíclica de Roberts es compartida por Shaikh (2010), quien afirma que la burbuja financiera de Estados Unidos impulsó la crisis, pero no la causó. Para este autor, esta crisis es parte de un patrón recurrente de la acumulación capitalista, en la que los periodos de auge eventualmente dan lugar a fases de declive.

Por su parte, Guerrero (2009) sostiene que la economía no se ha recuperado del estancamiento relativo de los últimos treinta años, a partir de la crisis de sobreacumulación de capital productivo, lo que se refleja en la crisis financiera. De manera que, para Guerrero, se ha producido una doble crisis: sobreacumulación de capital productivo e hipertrofia de la burbuja financiera, que será posible superar solamente mediante la destrucción de capital.

Para Astarita (2009), la crisis que está en curso es una crisis financiera con un trasfondo de plétora de capital "que, a su vez, se explica por una crisis no resuelta de sobreacumulación del capital á la Marx" (Astarita, 2009, p. 61). En otras palabras, la crisis no se debe a la supremacía del capital financiero sobre el capital industrial y comercial, "como si este último quisiera invertir y el capital financiero se lo impidiera absorbiendo el excedente $^{\prime \prime}$, sino a las contradicciones de la acumulación capitalista, de forma específica, por la alta relación Capital/Trabajo (la tendencia decreciente de la tasa de ganancia). Es decir, la inversión no era débil porque el capital financiero se imponía, "la realidad es que el 
capital financiero crecía porque la inversión era débil" (Astarita, 2009, p. 253).

Es entonces el neoliberalismo "la expresión política e ideológica de la orientación de fondo que ha tomado la clase capitalista a nivel mundial. Orientación que responde a la división central de la sociedad actual, la que se da entre capital y trabajo" (Astarita, 2010).

Otro autor crítico a la tesis de la financiarización es Andrew Kliman (2011), quien manifiesta que uno de los principales puntos de la tesis de la financiarización, la recuperación de la tasa de ganancia a partir de la crisis de la década de 1970, es errónea. Tal aseveración la realiza desde la crítica a la metodología de estimación de autores como Duménil y Lévy.

Kliman (2011) sostiene que luego de la crisis de la década de 1970 no hubo una restauración de la tasa de ganancia, debido a que no se generó una suficiente pérdida de valor de los activos para alcanzar una situación que permitiera la recuperación. De ahí que Kliman afirme que los bajos niveles de acumulación son resultado de la persistente caída de la tasa de ganancia. Esto, a su vez, conduce a un lento crecimiento del PIB per cápita, ventas de las empresas, compensación a trabajadores y el incremento de la carga de la deuda.
Kliman relaciona el constante decrecimiento de la tasa de ganancia con el incremento de la carga de la deuda. De manera que, desde la perspectiva de este autor, estas tendencias poseen la capacidad explicativa de las constantes crisis de origen financiero, la crisis de la deuda externa en la década de los ochenta, crisis financiera en México (efecto tequila, 1994), el sudeste asiático (efecto dragón, 1997), Rusia (efecto vodka, 1998), Brasil (efecto caipirinha, 1999), Argentina (efecto tango, 2000), la crisis bursátil vinculada a las empresas informáticas (burbuja punto com, 2001) y la crisis financiera actual, vinculada a los mercados inmobiliarios, es entonces una crisis más en esa línea.

Según Kliman (2011), es necesario reformular el análisis del papel de las políticas neoliberales en la economía. Las medidas de liberalización y desregulación, afirma, han formado parte de la necesidad del capital para su valorización a partir de los exiguos niveles de la tasa de ganancia. De manera que el neoliberalismo y el capitalismo financiarizado son consecuencia de la tendencia (decreciente) de la tasa de ganancia; en la situación actual, sostiene, estos elementos han estimulado la crisis pero no son su origen. Por ende, la propuesta de salida de crisis de Kliman, más allá de la superación del neoliberalismo, está vinculada con el abandono del modo de producción capitalista. 
De manera más sistematizada, se presenta una contrastación de las teorías en la tabla 1.1.

\section{Tabla 1.1. Contrastación de las teorías abordadas}

\begin{tabular}{|c|c|c|c|}
\hline & MONETARISTA & KEYNESIANA & MARXISTA $^{1}$ \\
\hline PREMISAS & $\begin{array}{l}\text { El sector financiero-mone- } \\
\text { tario para comprender la } \\
\text { economía real. El sistema } \\
\text { económico desde lo } \\
\text { monetario. } \\
\text { La economía de mercado } \\
\text { capitalista es inherente- } \\
\text { mente estable. }\end{array}$ & $\begin{array}{l}\text { Integración del sector mone- } \\
\text { tario y real para comprender } \\
\text { los fenómenos económicos. } \\
\text { La economía de mercado } \\
\text { capitalista es inherentemente } \\
\text { inestable. }\end{array}$ & $\begin{array}{l}\text { El sistema capitalista } \\
\text { comprende leyes y contra- } \\
\text { dicciones que tendencial- } \\
\text { mente lo conducen a crisis. } \\
\text { Tendencia decreciente de la } \\
\text { tasa de ganancia. }\end{array}$ \\
\hline $\begin{array}{l}\text { VISIÓN GENERAL DEL } \\
\text { FUNCIONAMIENTO } \\
\text { DEL SISTEMA } \\
\text { ECONÓMICO }\end{array}$ & $\begin{array}{l}\text { En el largo plazo, el nivel } \\
\text { de producción y empleo } \\
\text { tienden, por la fuerzas de la } \\
\text { oferta y de la demanda, a sus } \\
\text { niveles naturales. } \\
\text { Existen leyes en el funcio- } \\
\text { namiento del sistema que } \\
\text { permiten su desarrollo } \\
\text { estable. }\end{array}$ & $\begin{array}{l}\text { La magnitud de la demanda } \\
\text { efectiva dictamina el nivel de } \\
\text { producción y empleo, que } \\
\text { siempre es insuficiente. } \\
\text { Se necesitan estímulos para } \\
\text { que la demanda compense } \\
\text { la oferta que se genera. } \\
\text { No existen leyes regentes } \\
\text { sobre el funcionamiento del } \\
\text { sistema. Es necesaria la inter- } \\
\text { vención estatal para alcanzar } \\
\text { la estabilidad. }\end{array}$ & $\begin{array}{l}\text { La competencia entre capita- } \\
\text { listas, por obtener ganancias } \\
\text { extraordinarias, conduce a la } \\
\text { tecnificación constante; que } \\
\text { concluye en la disminución } \\
\text { tendencial de la g'. } \\
\text { En el espacio temporal entre } \\
\text { la mercancía y la forma } \\
\text { dinero surge el crédito y } \\
\text { el sistema financiero. Su } \\
\text { despliegue posibilita y } \\
\text { potencia la reproducción } \\
\text { del capital, y así también, } \\
\text { sus contradicciones. } \\
\text { Existen leyes inherentes al } \\
\text { funcionamiento del sistema, } \\
\text { que a través de su desarrollo } \\
\text { lo limitan. }\end{array}$ \\
\hline $\begin{array}{l}\text { POLÍTICA } \\
\text { ECONÓMICA } \\
\text {-Monetaria (PM) } \\
\text {-Fiscal (PF) }\end{array}$ & $\begin{array}{l}\text { Preserva la estabilidad del } \\
\text { mercado. Neutralidad. } \\
\text { PM: } \\
\text { Crecimiento constante de } \\
\text { la oferta monetaria corres- } \\
\text { pondiente al crecimiento } \\
\text { económico esperado en el } \\
\text { largo plazo. } \\
\text { PF: } \\
\text { Equilibrio presupuestario. }\end{array}$ & $\begin{array}{l}\text { Revierte la inestabilidad del } \\
\text { mercado. No neutralidad. } \\
\text { PM: } \\
\text { Expansión o contracción } \\
\text { de la oferta monetaria ante } \\
\text { recesión o sobrecalenta- } \\
\text { miento, respectivamente. } \\
\text { PF: } \\
\text { Déficit o superávit } \\
\text { presupuestario. } \\
\text { Según corresponda. }\end{array}$ & \\
\hline PAPEL DEL ESTADO & Participación tecnocrática. & Intervención orientadora. & \\
\hline
\end{tabular}




\begin{tabular}{|c|c|c|c|}
\hline & MONETARISTA & KEYNESIANA & MARXISTA $^{1}$ \\
\hline CAUSAS DE LA CRISIS & $\begin{array}{l}\text { Desequilibrios monetarios } \\
\text { por ineficiente intervención } \\
\text { estatal. } \\
\text { Shocks externos. } \\
\text { Excesiva regulación de los } \\
\text { mercados. }\end{array}$ & $\begin{array}{l}\text { General } \\
\text { Disminución de la demanda } \\
\text { efectiva, en parte, por el } \\
\text { desincentivo a invertir por } \\
\text { el declive del rendimiento } \\
\text { esperado. } \\
\text { Crisis actual } \\
\text { A. Excesiva desregulación } \\
\text { de los mercados financieros. } \\
\text { B. Inestabilidad y fragilidad } \\
\text { de los mercados financieros. }\end{array}$ & $\begin{array}{l}\text { General } \\
\text { Necesidad del sistema capi- } \\
\text { talista para recuperar la } \\
\text { dinámica de valorización } \\
\text { del capital. } \\
\text { Crisis actual } \\
\text { A. La financiarización. Dico- } \\
\text { tomía entre el sector finan- } \\
\text { ciero y el productivo. } \\
\text { B. El progresivo decreci- } \\
\text { miento de la tasa de } \\
\text { ganancia (el neoliberalismo } \\
\text { y la financiarización como } \\
\text { consecuencias de ese } \\
\text { proceso). }\end{array}$ \\
\hline $\begin{array}{l}\text { POSTURA ANTE LA } \\
\text { CRISIS }\end{array}$ & $\begin{array}{l}\text { La política monetaria expan- } \\
\text { siva afecta las variables } \\
\text { reales en el corto plazo. } \\
\text { En el largo, solo afecta la } \\
\text { inflación. } \\
\text { La política fiscal expan- } \\
\text { siva tiene efecto crowding } \\
\text { out si el déficit fiscal se } \\
\text { financia con deuda, debido } \\
\text { al incremento en la tasa de } \\
\text { interés. Mientras que si se } \\
\text { financia con aumento en la } \\
\text { oferta monetaria se genera } \\
\text { inflación. } \\
\text { Lo monetario sobre lo fiscal. }\end{array}$ & $\begin{array}{l}\text { La política monetaria expan- } \\
\text { siva estimula el empleo. } \\
\text { Dada la rigidez de los sala- } \\
\text { rios nominales y la inflación } \\
\text { que se genera, la disminu- } \\
\text { ción de los salarios reales se } \\
\text { traduce en un mayor nivel } \\
\text { de empleo; siempre que esté } \\
\text { aunado a un aumento de la } \\
\text { demanda efectiva. } \\
\text { La política fiscal expansiva } \\
\text { potencia la demanda efec- } \\
\text { tiva, a través del gasto y los } \\
\text { impuestos. Traducido en el } \\
\text { crecimiento de la produc- } \\
\text { ción y el ingreso. } \\
\text { Lo fiscal sobre lo monetario. }\end{array}$ & $\begin{array}{l}\text { A. Existe un incremento } \\
\text { de las retribuciones por } \\
\text { dividendos como parte del } \\
\text { ingreso total, que encubre } \\
\text { la dinámica de la tasa de } \\
\text { ganancia. A su vez, produce } \\
\text { bajas tasas de acumulación. } \\
\text { La hegemonía financiera } \\
\text { como resultado de las polí- } \\
\text { ticas neoliberales. } \\
\text { B. El nivel del producto } \\
\text { económico se desacelera por } \\
\text { la disminución tendencial } \\
\text { de la tasa de ganancia, } \\
\text { producida por incrementos } \\
\text { en CNN. Provisionalmente, el } \\
\text { capital busca altas ganancias } \\
\text { a través del sector financiero, } \\
\text { ampliándolo y desplegando } \\
\text { el crédito; debilitando aún } \\
\text { más la inversión productiva. }\end{array}$ \\
\hline $\begin{array}{l}\text { IMPLICACIONES } \\
\text { POLÍTICAS Y } \\
\text { SOCIALES }\end{array}$ & $\begin{array}{l}\text { Las crisis son evitables } \\
\text { cuando la participación del } \\
\text { Estado es de tipo tecnócrata. } \\
\text { Recorte de gastos estatales. } \\
\text { Disminución de la seguridad } \\
\text { social. } \\
\text { Evitar aumento de deuda. }\end{array}$ & $\begin{array}{l}\text { Las crisis son evitables y } \\
\text { gestionables. } \\
\text { La aplicación de políticas } \\
\text { económicas y sociales } \\
\text { adecuadas conlleva al } \\
\text { correcto funcionamiento del } \\
\text { capitalismo. } \\
\text { Mayor intervencionismo } \\
\text { estatal para alcanzar la esta- } \\
\text { bilidad del sistema a través } \\
\text { de la regulación. }\end{array}$ & $\begin{array}{l}\text { A1. El modelo económico } \\
\text { neoliberal potenció la } \\
\text { financiarización. Es nece- } \\
\text { sario realizar un cambio de } \\
\text { modelo que posibilite el } \\
\text { despliegue de la acumula- } \\
\text { ción (Duménil y Levy). } \\
\text { A2 y B. Superar el capita- } \\
\text { lismo con nuevas relaciones } \\
\text { sociales de producción. }\end{array}$ \\
\hline
\end{tabular}




\begin{tabular}{|c|c|c|c|}
\hline & MONETARISTA & KEYNESIANA & MARXISTA $^{1}$ \\
\hline $\begin{array}{l}\text { VARIABLES } \\
\text { DETERMINANTES }\end{array}$ & $\begin{array}{l}\text {-Oferta monetaria } \\
\text {-Regulación de los mercados }\end{array}$ & $\begin{array}{l}\text {-Demanda efectiva } \\
\text {-Gasto público } \\
\text {-Impuestos } \\
\text {-Deuda (pública y/o privada) }\end{array}$ & $\begin{array}{l}\text {-Tasa de ganancia } \\
\text {-Inversión/ acumulación de } \\
\text { capital } \\
\text {-Financiarización }\end{array}$ \\
\hline
\end{tabular}

Fuente: Elaboración propia.

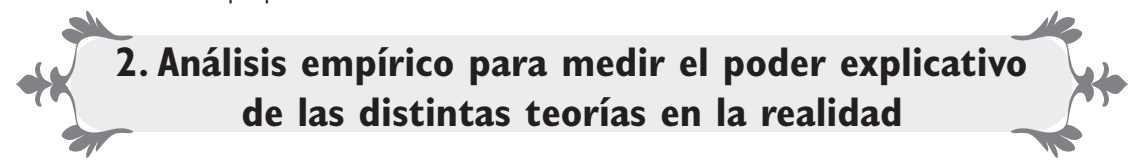

En este capítulo se realiza un estudio empírico para medir la capacidad de explicar la realidad que tiene cada escuela en torno a las crisis. Esta medición se lleva a cabo a través de la construcción de tres modelos econométricos para dos regiones, la Unión Europea (UE-15) y Estados Unidos.

Es fundamental enfatizar que el objetivo de la construcción de los modelos econométricos, es medir el poder explicativo de cada teoría con respecto a la realidad. En cada modelo se consideran las correspondientes variables identificadas por cada corriente de pensamiento como originadoras de las crisis.

Para la evaluación empírica del monetarismo se utilizará la tasa de variación del Producto Interno Bruto (PIB) como la variable que expresa la crisis; la Intervención Tecnocrática Monetarista (ITM) y el Índice de Regulación del Mercado (IRM), como variables que determinan el comportamiento del PIB.
La variable ITM permite evaluar el cumplimiento de la regla de oro monetarista. Como se explicó anteriormente, la regla monetarista se basa en la teoría cuantitativa del dinero. Por tanto, para mantener el equilibrio y no generar inflación, la teoría monetarista dicta la proporcionalidad en el crecimiento de la oferta monetaria (M) y el PIB. Así, la variable ITM expresa la divergencia entre ambas tasas de crecimiento, a través de la dispersión del ratio de $\dot{M}_{t}$ entre $P I \dot{B}_{t-1}$ con respecto a la unidad, de manera que es definida de la forma:

$$
I T M=\frac{\left(\text { ratio }_{t}-\mathbf{1}\right.}{\sqrt{\left(\frac{\sum_{t=1}^{n}\left((\llbracket \text { ratio }) \rrbracket_{t}-1\right)^{2}}{n-1}\right)}}
$$

El IRM es calculado por el promedio de las variables de tributos, subsidios y aranceles (TSA), formación bruta de capital fijo del sector público con respecto a la formación bruta de capital fijo total (FBKFpub/FBKB), regulación del mercado laboral (RMT) y la desregulación del mercado financiero (TF), en tasas de crecimiento. 


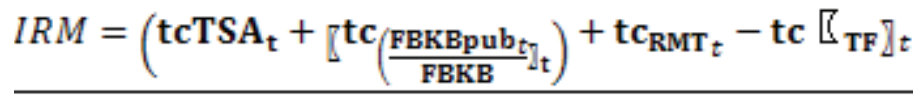 \\ 4}

Según la teoría monetarista, la relación entre la ITM y el crecimiento es negativa. Similar ocurre con respecto a la regulación de los mercados. De manera que el modelo es definido como:

$$
P I B_{t}=\hat{\beta}_{0}-\hat{\beta}_{1} I T M_{t-x}-\widehat{\beta}_{2} I R M_{t-x}+\widehat{u_{t}}
$$

Las variables a utilizar para el keynesianismo son la Tasa de Interés (TI), los Activos Financieros de la Deuda (AFD) y la Tasa de Financiarización (TF) como determinantes de la Demanda Efectiva (DE).

DE se refiere al consumo total de los hogares, del gobierno total y de organizaciones no gubernamentales.

La TI se emplea para identificar la dinámica de la eficiencia marginal del capital, de acuerdo a la teoría keynesiana, y su impacto en la demanda efectiva.

Los AFD hacen referencia a la parte de los activos financieros, títulos y valores que participan en la deuda privada. Esta variable es fundamental para los keynesianos que sostienen que la deuda privada ha servido para potenciar la crisis actual, y de esta forma justificar los enormes déficits públicos como una consecuencia de la crisis actual. Es calculada como el peso relativo de la diferencia entre los agregados monetarios M3 y $\mathrm{M} 2$ en la deuda privada total.

$$
A F D_{t}=\frac{\left(M 3_{t}-M 2_{t}\right)}{D P_{t}}
$$

La TF se implementa para analizar el impacto de la desregulación financiera en la demanda efectiva (Álvarez, 2012, p. 906).

Así, el modelo para la evaluación de la teoría keynesiana se establece como:

$$
D E_{t}=\widehat{\beta}_{0}-\widehat{\beta}_{1} T I_{t}-\widehat{\beta}_{2} T F_{t}-\widehat{\beta}_{3} A F D_{t}+\widehat{u_{t}}
$$

El modelo marxista se construye a partir de la Tasa de Acumulación (TAK) como variable dependiente de la Tasa de Ganancia (TG) y la Tasa de Financiarización (TF).
La TAK se refiere al cambio en el stock neto de capital fijo (SNKF). Esto es, el stock de capital fijo, ajustado por inflación y depreciación.

$$
T A K_{t}=\frac{\left(S N K F_{t}-S N K F_{t-1}\right)}{S N K F_{t-1}}
$$


La TG es calculada a partir del excedente bruto de explotación (EBE) en términos del stock neto de capital fijo.

$$
T G_{t}=\frac{E B E_{t}}{S N K F_{t}}
$$

La TF, Según Álvarez (2012 p. 906), permite observar la divergencia entre el excedente bruto de explotación (EBE) y la inversión productiva, medida a través de la formación bruta de capital fijo (FBKF).

$$
T F_{t}=\left(\frac{E B E_{t}}{P I B_{t}}\right)-\left(\frac{F B K F_{t}}{P I B_{t}}\right)
$$

\section{Tabla 2.1. Compilado de principales estadísticos estimados para}

\section{Estados Unidos}

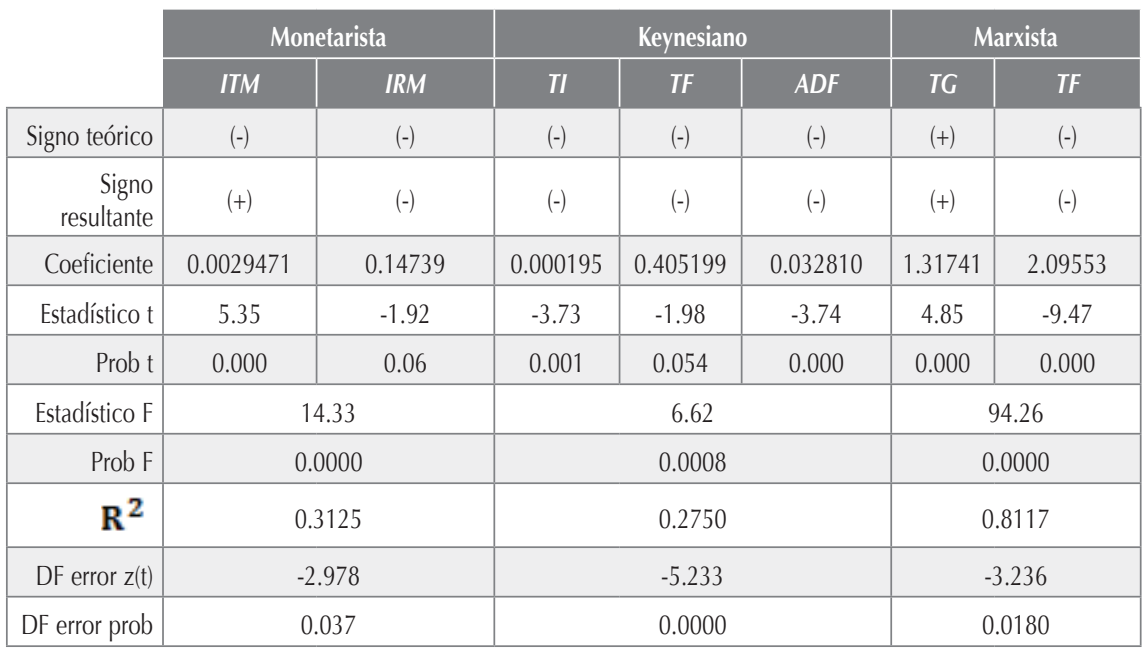

Fuente: Elaboración propia con base en resultado de regresiones de series de AMECO, NIPA, FED y BCE. 


\begin{tabular}{|c|c|c|c|c|c|c|c|}
\hline & \multicolumn{2}{|c|}{ Monetarista } & \multicolumn{3}{|c|}{ Keynesiano } & \multicolumn{2}{|c|}{ Marxista } \\
\hline & ITM & IRM & TI & TF & $A D F$ & IG & IF \\
\hline Signo teórico & $(-)$ & $(-)$ & $(-)$ & $(-)$ & $(-)$ & $(+)$ & $(-)$ \\
\hline Signo resultante & $(+)$ & $(-)$ & $(-)$ & $(+)$ & $(-)$ & $(+)$ & $(-)$ \\
\hline Coeficiente & 0.0027079 & 0.25126 & 0.000044 & 0.560808 & 1.34120 & 4.56080 & 1.16737 \\
\hline Estadístico t & 2.45 & -2.41 & -1.83 & 2.35 & -2.85 & 10.91 & -10.29 \\
\hline Prob t & 0.024 & 0.026 & 0.079 & 0.026 & 0.008 & 0.000 & 0.000 \\
\hline Estadístico F & \multicolumn{2}{|c|}{5.44} & \multicolumn{3}{|c|}{3.76} & \multicolumn{2}{|c|}{76.81} \\
\hline Prob F & \multicolumn{2}{|c|}{0.0136} & \multicolumn{3}{|c|}{0.0228} & \multicolumn{2}{|c|}{0.0000} \\
\hline $\mathbf{R}^{2}$ & \multicolumn{2}{|c|}{0.4304} & \multicolumn{3}{|c|}{0.5070} & \multicolumn{2}{|c|}{0.8402} \\
\hline DF error $z(t)$ & \multicolumn{2}{|c|}{-4.433} & \multicolumn{3}{|c|}{-4.653} & \multicolumn{2}{|c|}{-4.057} \\
\hline DF error prob & \multicolumn{2}{|c|}{0.0003} & \multicolumn{3}{|c|}{0.0001} & \multicolumn{2}{|c|}{0.0011} \\
\hline
\end{tabular}

Fuente: Elaboración propia con base en resultado de regresiones con series de NIPA, AMECO, FED y BCE.

Los resultados de la medida de bondad de ajuste que expresan el poder explicativo de las variables independientes frente a la dependiente. Por una parte, para el caso de Estados Unidos, el menor $R^{2}$ $R^{2}$ es resultado de la estimación del modelo keynesiano (0.2750) seguido del modelo monetarista (0.3125). Por otra parte, para el caso de UE-15, el modelo monetarista presenta un $R^{2} R^{2}$ de 0.4304 y el modelo keynesiano refleja un $R^{\mathbf{2}}$ $R^{2}$ de 0.5070 . Mientras, la estimación para la teoría marxista indica la mayor capacidad explicativa, con el mayor $R^{\mathbf{2}} R^{\mathbf{2}}$ en ambas regiones (0.8117 y 0.8402$)$.

Es, además, destacable la diferencia entre las relaciones teóricas de las variables y las obtenidas como resultado de la estimación.
Así, el modelo monetarista sugiere una divergencia con los signos $y$, por tanto, una objeción empírica a esta teoría: si bien muestra una relación inversa entre el crecimiento del PIB y la regulación de mercados en concordancia con los planteamientos monetaristas, la relación con respecto a la política monetaria es opuesta a lo teóricamente planteado.

También cabe resaltar la poca relevancia que tiene el cumplimiento de la regla de oro monetarista, expresada en el coeficiente del ITM como determinante del crecimiento, resultado que coincide para la UE15 y Estados Unidos. Esto último, aunado a la divergencia de signos, sugiere sustento empírico a la propuesta de política monetaria expansiva keynesiana. 
Los resultados de la estimación estadística del modelo keynesiano para Estados Unidos reflejan concordancia con los planteamientos de esta corriente, en cuanto a la relación entre variables. Sin embargo, para el caso de UE15, se presenta una discordancia con respecto a la relación con el despliegue de los mercados financieros, con la tasa de financiarización, y la dinámica de la demanda efectiva.

Es importante observar el mayor impacto de la financiarización sobre la demanda efectiva, para el caso de Estados Unidos. Esto permite inferir que se podría impulsar la demanda efectiva controlando los mercados financieros. Por otro lado, para el caso de la UE15, el mayor impacto lo presentan los AFD, de manera que, incrementos en la demanda efectiva se podrían realizar mediante el control de las finanzas estructuradas, limitando el mercado de derivados.

En la estimación del modelo marxista, todas las relaciones planteadas teóricamente se cumplen en la aproximación empírica realizada. Esto indica un mayor sustento empírico a la base teórica desarrollada por esta corriente.
Para el caso de Estados Unidos, tiene mayor peso relativo, a partir de los coeficientes, la tasa de financiarización. Sin embargo, la progresividad de este peso relativo y la relación inversa entre la financiarización y la tasa de ganancia permite inferir que la tendencia de la tasa de acumulación es dictada por la tendencia de la tasa de ganancia, mientras que la financiarización está más vinculada a la expansión de la deuda por los exiguos niveles de la tasa de ganancia $y$, por tanto, da cuenta de una etapa del proceso de acumulación con una agudización en la contradicción capital-trabajo.

Por otro lado, el mayor impacto sobre la tasa de acumulación de la UE15 lo presenta la tasa de ganancia, de manera que, la dinámica de la acumulación está relacionada con los movimientos de la tasa de ganancia. La menor influencia de la financiarización, contrario al caso de Estados Unidos, podría estar vinculada con el menor desarrollo de las finanzas estructuradas en esta región.

La fuerte relación entre las variables marxistas, sustentando su planteamiento teórico, proporciona insumos para concluir con la endogeneidad de las crisis a partir del desarrollo de las contradicciones del propio sistema. 


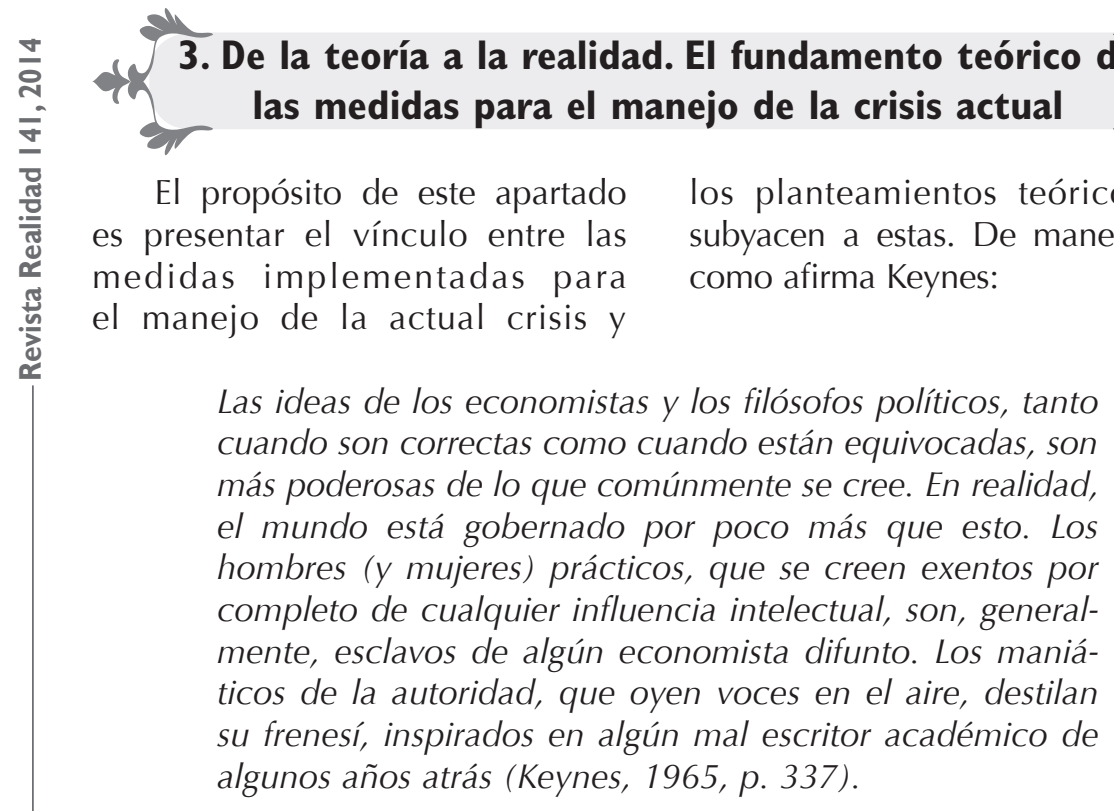

Muchas de las acciones seguidas por las distintas esferas de la sociedad, tanto desde la administración pública, las corporaciones y algunos movimientos sociales, tienen su fundamento, o encuentran justificación, en los desarrollos teóricos previamente abordados, que brindan diferentes interpretaciones a la comprensión de la realidad.

Los efectos de esta crisis han sido diferenciados para las clases que se derivan de las relaciones sociales de producción. Estas relaciones condicionan el proceso de la vida social a través del cual se genera un estado de dominación, que formula determinadas relaciones de poder. Por tanto, las medidas adoptadas responden a intereses de la clase que ejerce el poder más que a los de la sociedad como conjunto.

\subsection{La problemática en torno al abismo fiscal en Estados Unidos}

La estructura económica, como fundamento histórico de la producción material, se encuentra a la base de un proceso de construcción de un ideario colectivo, es decir, la forma de la conciencia social. Esto plantea repercusiones tanto en el ámbito académico como político. Por un lado, las teorías predominantes mantienen coherencia con los intereses de la clase que ejerce el poder. Y por otro lado, los políticos (entendiendo la política en su sentido estricto ${ }^{2}$ ) utilizan estas teorías predominantes como respaldo para justificar su accionar. 
De esta manera, los sucesivos gobiernos de EE.UU. impulsaron la desregulación de los mercados y disminuyeron el control sobre los movimientos de capital, promoviendo así la especulación y el excesivo apalancamiento de las instituciones financieras que terminarían por inflar la burbuja inmobiliaria (Girón y Chapoy, 2009, p. 50).

Para mediados de 2007, se observaron rápidos decrecimientos en el valor de los activos financieros en los mercados internacionales, esto ocasionó problemas de liquidez y crédito en bancos que estaban expuestos al mercado subprime en EE.UU.

Ante tal situación, se implementaron un conjunto de medidas compuestas por disminuciones en la tasa de redescuento, inyecciones de liquidez a través de la compra de acciones y estímulos fiscales; planteadas con el propósito de estimular la demanda a través del crédito. Dicho objetivo se corresponde con los planteamientos keynesianos.

Sin embargo, el proceso de salvataje e implementación de estas medidas responde a la necesidad del capital frente a sus problemas de valorización. Los intereses de clase sobre los que se erigen estas medidas se manifiestan en la orientación de fondos para estimular la demanda, destinados a bancos y grandes corporaciones, en lugar de dirigirse a mejorar las condiciones de la clase trabajadora, por ejemplo.

Lo anterior se refleja en que, si bien el gobierno estadounidense reducía constantemente la tasa de referencia, con el objetivo de disminuir las demás tasas de interés, las tasas a las que se endeudaban los hogares seguían aumentando, perjudicando el crédito y desestimulando el consumo (Astarita, 2009, p. 122).

El rescate de Fannie Mae y Freddie Mac significó un alto grado de intervencionismo estatal. Sin embargo, a inicios de septiembre de 2008, el gobierno se niega a rescatar a Lehman Brothers, el cuarto banco de inversión en EE.UU, y retoma su postura monetarista de no intervencionismo estatal escudándose en el riesgo moral.

En ese mismo año, se enfrenta la posible caída de la aseguradora American Internacional Group (AIG). Para ello, se abandona la postura del riesgo moral y se sustituye por el argumento de too big to fall (demasiado grande para que caiga). El gobierno retoma medidas keynesianas e interviene tomando el control de parte de las acciones preferentes de AIG.

La inconsistencia en el rescate de AIG, Fannie Mae y Freddie Mac, a diferencia de lo ocurrido con Lehman Brothers, denota nuevamente la influencia de intereses generados a partir de la necesidad 
de valorización del capital, para el manejo de la crisis. Las empresas que se rescataron jugaban un papel fundamental en el sostenimiento de la dinámica del sistema financiero. Mientras que las demás, como Lehman Brothers, solo formaban parte de esta dinámica. Esto se traduce en un proceso de concentración y centralización del capital, propio del capitalismo, que se recrudece en los períodos de crisis.

Para finales de septiembre de 2008, se presentó un plan que consistía en la compra de las hipotecas subprime. Esta medida representaría el mayor intervencionismo estatal en la era de G.W. Bush; sin embargo, el Congreso de los EE.UU. rechazó la propuesta de nacionalización de las hipotecas ocasionando mayor incertidumbre y un nuevo desplome en los mercados financieros (Astarita, 2009, p. 134).

En esta ocasión, fue el Congreso el que optó por rechazar esta propuesta que incluía medidas de corte keynesiano, rechazo que se corresponde con una visión - fundamentada en los planteamientos monetaristas-, de los ajustes automáticos del mercado. De esta manera se pretendía limitar el papel del Estado y se restringía la capacidad de la FED en cuanto a las medidas para el manejo de la crisis.

Por otro lado, las medidas de incremento al gasto público, a pesar del déficit fiscal propuestas por la administración Obama, se pueden vincular con los planteamientos keynesianos de Galbraith. Sin embargo, el escepticismo en cuanto a las medidas con inclinaciones keynesianas sigue estando presente en la mayoría de líderes y sectores de la academia vinculados con teorías que responden a los intereses de los grandes conglomerados financieros, es decir, a la valorización del capital.

Los planes de recuperación económica del gobierno de Obama aumentaron el nivel de endeudamiento estadounidense hasta alcanzar el límite permitido por el Congreso. Por un lado, los demócratas demandaban que se les permitiera sobrepasar el nivel de endeudamiento establecido, y por otro lado, los republicanos exigían serios recortes en el gasto público. Finalmente, se optó por una salida temporal y se decidió aumentar el techo de la deuda, y de esta manera incentivar a los congresistas a llegar a un futuro acuerdo en cuanto a la reducción del déficit fiscal (Chirinos, 2012).

Tras una serie de desacuerdos entre republicanos y demócratas se acordó, para el primero de enero del 2013, aumentar los impuestos de los sectores que poseen un mayor nivel de ingresos, con el objetivo de reducir el déficit fiscal. De igual manera, se acordó prorrogar los recortes 
presupuestarios durante los primeros meses del año.

Las medidas implementadas por el gobierno estadounidense para el manejo de la crisis, incluyendo el debate sobre el abismo fiscal, son parte de la dinámica de estabilización económica a partir de la deuda que se venía gestando en las últimas décadas. Con la particularidad, que a través de la intervención pública, la sociedad subsidia los problemas de acumulación del capital.

A raíz de esto, desde algunos sectores se adquiere conciencia de la contradicción del desarrollo en el capitalismo, lo que desemboca en el surgimiento de movimientos sociales como Ocupa Wall Street. Sin embargo, la heterogeneidad en la naturaleza de estas movilizaciones, diluye el cuestionamiento a las relaciones sociales de producción y se centran en la órbita de distribución ${ }^{3}$.

Así, como se ha podido observar, las medidas tomadas responden a la necesidad de recuperar la tasa de ganancia capitalista, lo que explica la inconsistencia en el planteamiento teórico que las respalda. Empero, el marco general en el que se aplican estas medidas está influenciado por una visión monetarista de libre mercado, que como fue demostrado anteriormente, bajo los criterios y parámetros establecidos, es la que menor capacidad explicativa posee.
De manera que, el predominio de esta visión en las medidas aplicadas responde a una visión enmarcada a los intereses de clase, vinculados con la reproducción del capital.

\subsection{La Unión Europea y el debate sobre la austeridad}

Europa, durante las últimas décadas, se ha mantenido en la búsqueda de la integración europea con una política monetaria única en aras de mantener la inflación controlada, lo que se fundamenta en planteamientos teóricos monetaristas. Por un lado, la integración económica promueve la desregulación de los mercados, mientras que por otro, la creación del euro busca la tecnocratización monetarista de las políticas monetarias a través del Banco Central Europeo (BCE).

Estos procesos de integración, bajo los objetivos planteados, aseguraban las condiciones de la valorización del capital. Asimismo, limitaba los márgenes de maniobra de los Estados miembros a la política fiscal, en donde el gasto público quedó restringido por las medidas de austeridad, que ha derivado en privatizaciones y progresivas disminuciones al gasto público. Esto, conllevó a la pérdida de acceso a los servicios públicos, lo que aunado a los salarios como mecanismo de ajuste, posiciona a la clase trabajadora en un estado de vulnerabilidad. 
Esta dinámica refleja la contradicción capital-trabajo en el desarrollo capitalista y su influencia en la implementación de políticas. Además, esta misma contradicción, a través de los mecanismos de la competencia, ha llevado a un proceso de deterioro general de las condiciones de la clase trabajadora de los Estados miembros, que ha impactado en mayor medida a la periferia europea (i. e. Portugal, Italia, Grecia y España).

Lo anterior, en la medida en que los países de menor tecnificación —países de la periferiatransfieren valor a los de mayor tecnificación — países del centro (i. e. Alemania, Holanda, Francia, Austria)—, bajo los mecanismos de la competencia. La búsqueda de competitividad en la periferia europea, llevó a realizar ajustes en los costos, en particular a través de salarios.

En las economías centrales se promovía el incremento de las exportaciones por el detrimento de la demanda interna. En las economías periféricas, crecimiento sustentado en la demanda interna a través del endeudamiento. Esto ocasionó crecimiento del déficit de la cuenta corriente en la periferia compensado con flujos de capitales provenientes del centro.

Esta dinámica centro-periferia en la UE propició, por un lado, la heterogeneidad de la estructura productiva a favor de los países del centro, y por el otro, la gestación de burbujas especulativas.

Estas condiciones, combinadas con las políticas de desregulación de los mercados, fortaleció el vínculo del sistema financiero europeo con el estadounidense. Parte de los activos financieros europeos se incorporaron a las finanzas estructuradas estadounidenses, volviéndolos vulnerables a las fluctuaciones de estos últimos.

Debilidades que, junto a la desigualdad inherente al proyecto europeo, propiciaron el entorno ideal para la llegada de la crisis financiera actual a Europa. Esto provocó el desplome del valor de los activos financieros europeos e impulsó la contratación de deuda por parte de los bancos.

Frente a este panorama, la Comisión Europea (CE) presentó el Plan Europeo de Recuperación Económica (PERE). Este se formuló bajo dos objetivos fundamentales, por un lado, fortalecer la competitividad y por el otro, impulsar la demanda. Para alcanzar estos objetivos, en el PERE se presentaron un conjunto de medidas que consistían en el incremento del gasto y reducción de impuestos, ambas sujetas a las condiciones establecidas en el Pacto de Estabilidad y Crecimiento (PEC) (Comisión Europea, 2008). 
Las medidas aplicadas que se recomendaban en el PERE, fueron aquellas que respondían a las necesidades de valorización del capital y, por tanto, a los intereses de la clase que ejerce el poder en la estructura económica.

Por tal razón, las propuestas en relación al aumento del gasto público en contribuciones sociales fueron obviadas. Muchas de las deudas contratadas por privados fueron adquiridas por parte de los gobiernos, con el objetivo de sanear la banca y evitar el desplome del sistema financiero europeo.

El rescate de los bancos por parte de los gobiernos, medida con trasfondo teórico keynesiano, indica, al igual que para Estados Unidos, que dicha orientación de liquidez responde a la preeminencia de los intereses de la clase capitalista, en tanto son coherentes con la lógica de acumulación del capital.

Esta contraposición de medidas llevó a un aumento del déficit público a partir de la absorción de la deuda privada, generada en la dinámica de las finanzas estructuradas (ver gráfico 3.1). Por tanto, es erróneo afirmar que este incremento en el déficit fue ocasionado por el aumento en el gasto público y el mantenimiento del Estado de Bienestar, como sostiene la versión oficial.

\section{Gráfico 3.1. Deuda pública y privada pre-crisis y poscrisis en UE-15 (Índice 2005=100)}

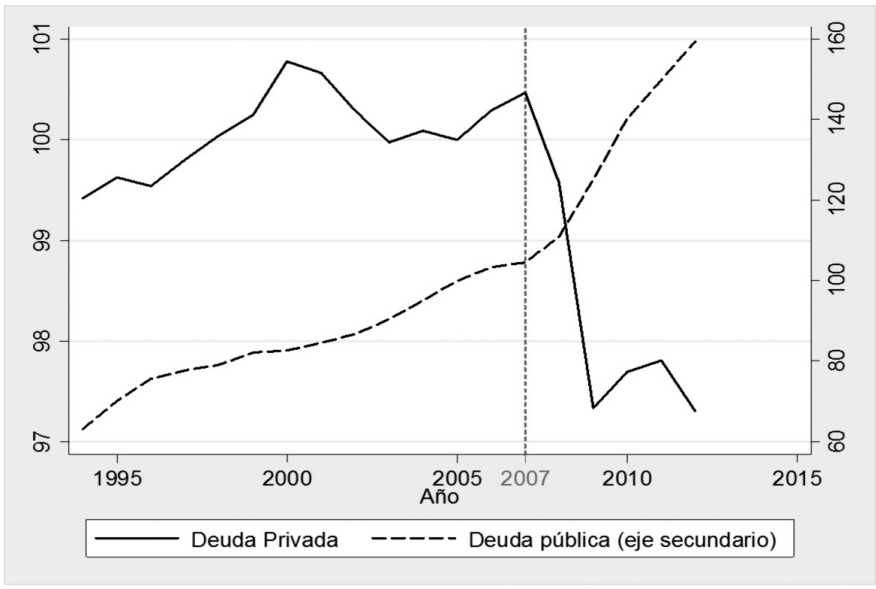

Fuente: Elaboración propia con base en AMECO.

Ante este panorama de un elevado nivel de déficit (contrario a los objetivos buscados por la teoría monetarista), la UE justifica 
la exigencia, de manera inmediata, de una reducción significativa del déficit público, por medio de un rígido plan de austeridad.

Las medidas de austeridad $y$ recortes sociales han estado influenciadas por la denominada Troika, compuesta por la CE, el
BCE y el FMI, y son presentadas como una receta tecnocrática de respuesta a la crisis, visión propia de la corriente monetarista. Cabe destacar que estos organismos responden, de facto, a los intereses de los países miembros con mayor poder económico.

Tabla 3.1. Poder económico y poder de decisión de los cinco principales miembros del FMI, BCE y CE

\begin{tabular}{|l|c|c|l|c|c|c|c|}
\hline \multicolumn{2}{|c|}{ Fondo Monetario Internacional } & \multicolumn{3}{c|}{ Banco Central Europeo } & \multicolumn{2}{c|}{ Comisión Europea } \\
\hline País & $\begin{array}{l}\text { Aportación } \\
\% \text { del total) }\end{array}$ & $\begin{array}{l}\text { Poder de voto } \\
\% \text { del total) }\end{array}$ & Pais & $\begin{array}{l}\text { A portación } \\
\text { \% del total) }\end{array}$ & $\begin{array}{l}\text { Representantes } \\
\text { en Comité } \\
\text { Ejecutivo }\end{array}$ & $\begin{array}{l}\text { País } \\
\text { Poder de voto } \\
\% \text { del total) }\end{array}$ \\
\hline Estados Unidos & 17.69 & 16.75 & Deutsche Bundesbank (Alemania) & 18.76 & $2 / 6$ & Alemania & 8.41 \\
\hline Japón & 6.56 & 6.23 & Bank of England (Reino Unido) & 14.43 & 0 & Reino Unido & 8.41 \\
\hline Alemania & 6.12 & 5.81 & Banque de France (Francia) & 14.13 & $1 / 6$ & Francia & 8.41 \\
\hline Francia & 4.51 & 4.29 & Banca d'Italia (Italia) & 12.45 & $1 / 6$ & 8.41 \\
\hline Reino Unido & 4.51 & 4.29 & Banco de España (España) & 8.25 & 0 & España & 7.82 \\
\hline
\end{tabular}

Fuente: Elaboración propia con base en FMI, BCE y Tratado de Lisboa.

Lo anterior, se ve reflejado en el paquete de rescate a Grecia en 2009, con una combinación de préstamos bilaterales de países de la eurozona y del Fondo Monetario Internacional (FMI), condicionado a un plan de reformas que buscaban disminuir el déficit mediante una reducción del gasto público e incremento de impuestos.

Un paquete similar fue aplicado en España, donde la reforma incluía, además, una flexibilización del mercado laboral, mediante reducción de horas de trabajo trabajo a medio tiempo- y por ende disminución de salarios. Esta reforma se justificó con la posible reducción del desempleo, continuando con la visión monetarista impuesta por la Troika europea.

La producción de ideas se corresponde a las condiciones de la producción material, de manera que, el modo de producción material determina el proceso de producción de las ideas. Así, un modo de producción con una estructura económica de clases, cuya búsqueda se centra en el proceso de acumulación de capital, sostiene un ideario colectivo que asegura las condiciones de reproducción del sistema.

Por tal razón, la investigación de Reinhart y Rogoff (2010) ha sido utilizada como argumento para defender estas medidas de austeridad. Estos autores plantean que el 
crecimiento económico sufre una disminución cuando incrementa el tamaño de la deuda de un país; por encima del $90 \%$ del PIB, el crecimiento sería de $-0.1 \%$.

Sin embargo, para Herndon (2013), existe una inconsistencia en los resultados obtenidos por Reinhart y Rogoff; de manera que, las economías con una deuda por encima del $90 \%$ del PIB, crecen a un $2.2 \%$.

Esta investigación se enmarca en un proceso de crítica a las medidas de austeridad desde diferentes sectores, en este caso desde el establishment, que además propone adoptar medidas fundamentadas en el planteamiento keynesiano.

Este conjunto de propuestas, a pesar de las confrontaciones y matices en sus bases teóricas keynesianas y monetaristas-, son resultado del mismo ideario colectivo que busca asegurar las condiciones de reproducción del sistema. Bajo esta dinámica, en 2013, la CE ha propuesto la creación de un fondo común de rescate bancario, como medida precautoria ante las posibles quiebras de bancos.

Asimismo, los recortes del Estado de Bienestar europeo han sido bajo la lógica de relanzar el proceso de acumulación de capital. En consecuencia a esta contradicción capital-trabajo, se gestan las condiciones históricas para la formulación de alternativas al sistema.
A partir de la conciencia de estas contradicciones, algunos grupos se han movilizado para manifestarse en contra del desarrollo del modo de producción capitalista, como el movimiento $15-M$ de España y sus similares en diversos países de Europa.

Además, la recuperación de la rentabilidad del capital se ha fundamentado en incrementos en la tasa de explotación, mediante la flexibilización laboral y los recortes en la seguridad social. Esto genera una creciente presión en el desempleo y la demanda por una alternativa de sobrevivencia fuera de la subsunción directa del capital. En esta línea, cobran ímpetu estrategias alrededor del comercio justo, economía comunitaria, bancos solidarios, cooperativismo y monedas sociales.

\subsection{Consideraciones generales}

De acuerdo con lo que se ha analizado en el desarrollo del capítulo, se puede establecer que las medidas adoptadas para solucionar la crisis no han estado fundamentadas en la teoría que mayor capacidad explicativa posee, según los parámetros y criterios establecidos (ver tabla 2.1 y 2.2), y más bien responden a la necesidad de relanzar el proceso de acumulación de capital. Por tanto, proveen una salida temporal a la crisis, manteniendo las causas subyacentes que la generan. El desarrollo de estas condiciones, bajo la contradicción 
capital-trabajo, gesta las condiciones para nuevas crisis, cada vez más frecuentes y severas.

El contexto de sobreexplotación y transferencia de valor, a través de la expoliación, que se ha desenvuelto en la periferia de la geoeconomía, se ha extendido a la periferia del centro. Esto, como mecanismo de respuesta a las necesidades de valorización del capital frente a los límites de esta dinámica en la periferia tradicional.

Desde este panorama, el apego a la teoría que mejor permite explicar el origen de las crisis, bajo los criterios y parámetros establecidos, permite inferir que una solución de fondo a las crisis pasa, necesariamente, por la superación del modo de producción capitalista.

Se precisa señalar que, la transición de un modo de producción a otro proviene de la convergencia de dos condiciones fundamentales. Por un lado, las circunstancias socioeconómicas, en referencia a la contradicción entre el desarrollo de las fuerzas productivas y las relaciones sociales de producción del orden vigente. Por otro lado, el movimiento histórico se genera a partir de enfrentamiento de clases, esto es, como producto de voluntades, expresadas en la movilización con fines revolucionarios.

Al cambiar la base económica se transforma, más o menos rápidamente, toda la inmensa superestructura erigida sobre ella. Cuando se estudian esas transformaciones hay que distinguir siempre entre los cambios materiales ocurridos en las condiciones económicas de producción (...) y las formas jurídicas, políticas, religiosas, artísticas o filosóficas, en una palabra, las formas ideológicas en que los hombres (y mujeres) adquieren conciencia de este conflicto y luchan por resolverlo. (Marx, 2001).

La transformación de las condiciones sociales, necesarias para un nuevo modo de producción, surge de las contradicciones en el desarrollo del propio capitalismo. De manera que las relaciones sociales de producción capitalistas impulsan el desarrollo de las fuerzas productivas, hasta convertirse en su propio obstáculo.
Bajo esta perspectiva, la confrontación con el modo de producción se genera en momentos donde se agudiza la conciencia de las contradicciones intrínsecas al desarrollo capitalista. Esto ocurre, necesariamente, luego de períodos de desarrollo de las fuerzas productivas, en tanto ese desarrollo genera el carácter contradictorio. 
Así, las crecientes movilizaciones en protesta al orden actual se pueden enmarcar, en este enfoque, como parte de la conciencia de estas contradicciones. No obstante, estas expresiones carecen de posibilidades de proyecto histórico, si no cuestionan la estructura social subyacente y se limitan a demandas inconclusas sobre las relaciones sociales de producción.

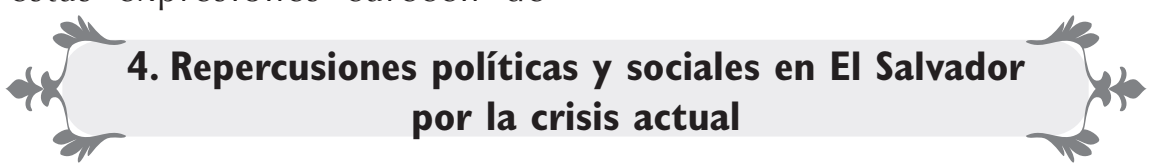

La dinámica de los programas de ajuste, que a partir de la crisis actual se aplican a la periferia del centro, posee un carácter similar que los aplicados, en las últimas décadas, en la periferia de la economía global para resolver las necesidades de valorización del capital, en periodos de crisis.

Una de las principales regiones involucradas con este tipo de programas de ajustes ha sido la latinoamericana, con países tradicionalmente subsumidos a los intereses de las naciones con mayor poder económico. Los países de la región están caracterizados, además, por una profunda dependencia y dominación en detrimento de su soberanía, lo que se puede reflejar en procesos de dolarización, como el caso de El Salvador.

Nuestro país, a partir de los años 90, adopta un conjunto de medidas financiadas e impuestas por el FMI y el Banco Mundial (BM) para llevar a cabo un cambio estructural. La puesta en marcha del Plan de Desarrollo Económico y Social, consistía en un Programa de Estabilización
Económica (PEE) y en un Programa de Ajuste Estructural (PAE).

Estas políticas económicas han estado fundamentadas en los lineamientos del consenso de Washington, enfocadas a impulsar una desregulación y liberalización económica, flexibilización del mercado laboral, desregulación a la inversión extranjera, privatización y liberalización del mercado financiero. De esta manera, los PAE-PEE han buscado ampliar la órbita de acumulación del capital. Desde esta misma perspectiva se enmarca la agenda de firmas de Tratados de Libre Comercio (TLC) y la dolarización.

\subsection{Mecanismos de transmisión}

Esta estrategia de liberalización y desregulación, bajo una visión monetarista de libre mercado, genera condiciones de vulnerabilidad al país. Por un lado, la fuerte dependencia del comercio internacional, $y$, por otro, el deterioro de las condiciones de la clase trabajadora que produce un elevado nivel de migración (aunado a los generados 
por el conflicto armado) y se traduce en importantes flujos de remesas que imprimen una dinámica particular a la economía salvadoreña.

Así, una de las principales manifestaciones de la crisis actual se observa en una disminución de las exportaciones y una contracción en las importaciones, para 2009 (ver gráfico 4.1). Esto, producto de la caída en la demanda externa y el deterioro de la demanda local, resultado de una disminución en las remesas ${ }^{4}$ (ver gráfico 4.2), expresión de las consecuencias de la crisis en los países más afectados directamente.

\section{Gráfico 4.1. Composición de los flujos de comercio entre EL Salvador y el resto del mundo (Millones de USD)}

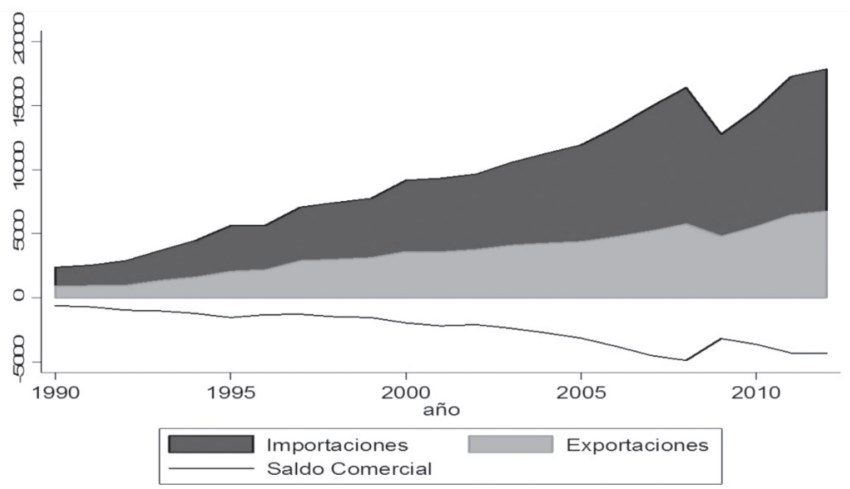

Fuente: Elaboración basada en datos del BCR.

\section{Gráfico 4.2. Incidencia de remesas en el déficit comercial}

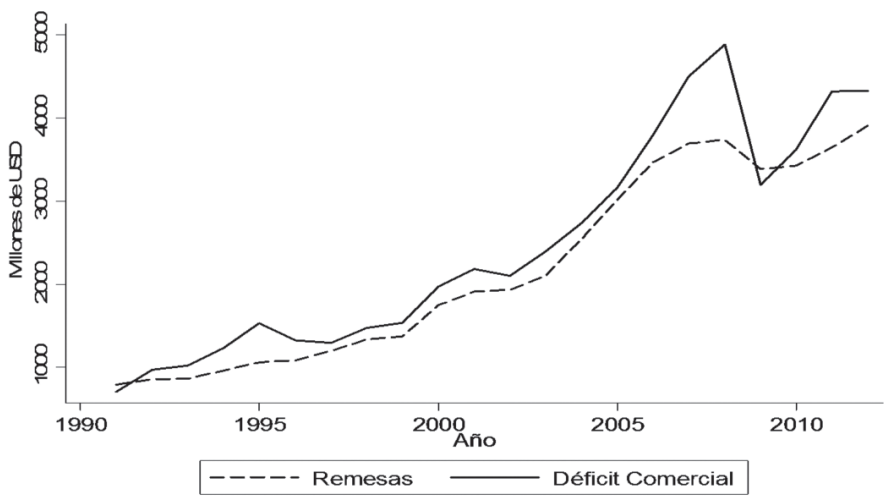

Fuente: Elaboración basada en datos del BCR. 
Las remesas, como fuerte potenciador del consumo, se vuelven una de las transferencias desde el exterior que permite sostener el crónico déficit comercial. Para 2008, el flujo de remesas disminuyó en un $9.49 \%$. Esta caída adquiere mayor relevancia, en tanto el crecimiento anual promedio de las remesas era del $12.44 \%$ en los cinco años anteriores.

\subsection{Manifestaciones de la crisis actual en El Salvador}

El comportamiento de las variables anteriores ha repercutido en la dinámica del crecimiento, así, ha existido un comportamiento cíclico con una tendencia a la disminución de la tasa de crecimiento del PIB. De 2005 a 2007, presenta una relativa estabilidad con tasas de crecimiento en promedio de $3.77 \%$. Para 2008, presentó un crecimiento de $1.27 \%$ y un año después experimentó la mayor tasa de decrecimiento, $3.13 \%$, como efecto de la crisis económica en El Salvador.

Estos resultados se pueden contrastar con las tendencias de la región latinoamericana y centroamericana. Para 2009, El Salvador registra la menor tasa de crecimiento respecto a ambas regiones.

Además, es importante considerar los efectos para la clase trabajadora, a partir de la evolución de los salarios reales, el nivel de desempleo formal y otras expresiones fuera de la órbita de subsunción directa del capital, como el subempleo.

En cuanto a los salarios reales, se ha tenido una tendencia a la baja, lo que refleja un detrimento del poder adquisitivo de los asalariados y asalariadas. En cuanto a los años del estallido de la crisis actual, para 2008 los salarios reales crecen $-2.2 \%$ y para $2009,-4.72 \%$.

Por otro lado, para 2009, el desempleo sufrió un incremento de $5.9 \%$ a $7.3 \%$. Sin embargo, las condiciones de valorización del capital en el país excluyen a gran parte de la población del empleo formal, esto es, de la subsunción directa del capital. De manera que, en este contexto, adquiere una mayor relevancia la dinámica del subempleo como subsidiaria del proceso de acumulación del capital. Como resultado de esto, persisten altas tasas de subempleo con un $44.3 \%$, entre 2002 y 2006. Posterior al estallido de la crisis, en 2009, se dio una alza del $40.6 \%$ al $44.3 \%$.

En términos de desigualdad en la distribución del ingreso, como expresión de la disputa distributiva entre las clases, se agudiza a partir del estallido de la crisis. Esto se puede interpretar como un retroceso de la clase trabajadora frente a la capitalista, debido a las condiciones ventajosas concedidas a esta última en aras de la valorización del capital. 
A partir de los indicadores presentados (salarios, subempleo, desempleo, desigualdad), se puede ver un proceso sistemático de la desvalorización de la fuerza de trabajo que se agudiza a raíz del estallido de la crisis actual. Esto, dado los serios problemas para el proceso de acumulación de capital en el país, resultado de la tendencia decreciente de la tasa de ganancia ${ }^{5}$.

\subsection{Medidas implementadas para el manejo de la crisis actual}

Al ser un país inserto en la periferia de la dinámica económica global, la formulación de política económica se encuentra limitada por una serie de imposiciones respecto a las directrices a seguir, de acuerdo al papel que desempeña en el proceso mundial de valorización del capital.

Esto se puede ver reflejado, en las condiciones impuestas por el FMI en el otorgamiento de préstamos, tanto con los PAE-PEE como con el acuerdo precautorio de 2009 y 2010. En este último se establecían medidas de disciplina fiscal (similar a la UE), medida con fundamento teórico monetarista. Bajo este mismo marco, se pueden comprender los compactos de FOMILENIO y el Asocio Para el Crecimiento - promovidos por Estados Unidos-, que establecen un conjunto de lineamientos que el gobierno debe cumplir. De esta manera, las medidas implementadas para el manejo de la crisis se corresponden a estas directrices.

En este mismo contexto, se han implementado, por un lado, medidas de corte keynesiano, como el estímulo al empleo, transferencias directas a sectores vulnerables y la reestructuración del Banco Multisectorial de Inversiones (BMI) por el Banco de Desarrollo de El Salvador (BANDESAL). Este tipo de medidas son una serie de concesiones del capital que garantiza su reproducción - profundiza la dependencia de la economía al comercio internacional (ver gráfico 4.1) - encubre las contradicciones del desarrollo capitalista y atomiza los movimientos sociales.

Por otro lado, se aplicaron medidas de corte monetarista, como austeridad en el gasto, focalización de subsidios y recortes en el sector público. La inconsistencia entre adopción de medidas keynesianas y monetaristas es parte de la misma dinámica de los países del centro y responden directamente a la necesidad de valorización del capital.

Las estrategias implementadas, para el manejo de la crisis actual, han generado un aumento significativo en el déficit público, al igual que en las economías del centro. A pesar de los diversos debates sobre esto, el endeudamiento posee un carácter sistémico a partir de la 
tendencia decreciente de la tasa de ganancia de la economía local y de las economías del centro.

Tal endeudamiento genera problemas de liquidez, argumento tras el cual se respalda la implementación del Acuerdo de Asociación con la Unión Europea en 2013 (ADA) que, de fondo, no es más que un Tratado de Libre Comercio (TLC). Ese mismo año se ratifica la Ley de Asocios Público-Privados (APP) que, a pesar que legalmente no constituye una privatización, mantiene el carácter del manejo privado de bienes y servicios públicos. Ambos concuerdan con la necesidad de ampliar la órbita de valorización y circulación del capital que, en última instancia, no es más que el continuo proceso de divorcio entre medios de producción y fuerza de trabajo.

Las medidas implementadas para el manejo de la crisis en el caso de El Salvador, en la actual era de la internacionalización del capital, responden a los intereses de las transnacionales. Por tal razón, El Salvador, por la geopolítica actual, no es partícipe en el debate sobre las medidas para el manejo de la crisis.

\section{Conclusiones}

A partir de las evidencias teóricas y empíricas recopiladas en el desarrollo de esta investigación, es posible concluir que las medidas económicas, adoptadas para enfrentar la crisis económica actual, no están fundamentadas en la teoría capaz de explicar de mejor manera el origen de la crisis en el capitalismo.

En este sentido, la eficacia de las medidas está limitada, en tanto no abordan las causas subyacentes al origen de la actual crisis del modo de producción capitalista. De manera que, los efectos derivados de estas medidas contribuyen, si bien a futuro, a una agudización de la crisis, más que a su resolución.
Las divergencias existentes entre las escuelas monetarista, keynesiana y marxista resultan de diferencias epistemológicas en cuanto a la comprensión de la realidad. Según sea el abordaje, las conclusiones giran en torno a la posibilidad de evitar o gestionar la crisis o si esta es, simplemente, parte de la dinámica propia del capitalismo.

Para los monetaristas, las causas de la crisis se atribuyen a desequilibrios monetarios por la ineficiente intervención estatal, shocks externos y excesiva regulación de los mercados. Por tanto, para esta corriente, la posibilidad de crisis no es inherente al modo de producción capitalista. 
En la corriente keynesiana, la crisis actual, en general, es atribuida a una excesiva desregulación de los mercados financieros y a la inestabilidad y fragilidad de los mismos. De esta manera, plantean que las crisis son evitables y gestionables a partir de la correcta aplicación de políticas económicas y sociales para el adecuado funcionamiento del capitalismo.

En el debate marxista de la crisis actual, las posturas principales se centran, por un lado, en la dicotomía entre capital financiero y capital productivo, resultado del proceso de financiarización, facilitado por el neoliberalismo; por otro, la tendencia decreciente de la tasa de ganancia genera una búsqueda de alternativas de rentabilidad a través del sistema financiero, lo que propicia las burbujas especulativas. Esto implica que la solución de la crisis pasa por la superación del capitalismo, mediante nuevas relaciones sociales de producción.

Los resultados presentados en la contrastación empírica, bajo los criterios y parámetros establecidos, demuestran el mayor poder explicativo de la teoría marxista frente a la realidad, con respecto a la teoría monetarista y keynesiana. Esto indica un mayor sustento empírico a la base teórica desarrollada por esta corriente.

Las medidas implementadas frente a la crisis no han estado fundamentadas en la teoría que mayor capacidad explicativa posee, y más bien responden a la necesidad de relanzar el proceso de acumulación de capital, por lo que proveen una salida temporal a la crisis, manteniendo las causas subyacentes que la generan. EI desarrollo de estas condiciones, bajo la contradicción capitaltrabajo, gesta las condiciones para nuevas crisis, cada vez más frecuentes y severas.

La inminente necesidad de la recuperación de la tasa de ganancia ha llevado a que los procesos de sobreexplotación y expoliación se extiendan a la periferia del centro, frente a los límites de esta dinámica en la periferia tradicional.

Para el caso de El Salvador, las medidas para el manejo de la crisis se enmarcan en el proceso mundial de recuperación de rentabilidad y, por tanto, responden a los intereses de los países con mayor poder económico a través de las presiones de las transnacionales y los organismos multilaterales.

Las crisis, en última instancia, son resultado de la agudización de la contradicción entre desarrollo de las fuerzas productivas y relaciones sociales de producción, contradicciones que, en el capitalismo, implican el conflicto capital-trabajo, relación fundamental de este modo de producción. Por tanto, y como ya fue señalado, la solución de 
fondo a las crisis económicas como la actual, pasa, necesariamente, por la superación histórica del capitalismo, y con él, de sus contradicciones y relaciones que condenan a la mayor parte de la población a la explotación y subyugación.

\section{Referencias bibliográficas}

os Álvarez, N., (2012). "Financiarización, acumulación de capital y ajuste salarial en la UE". Ponencia en XIII Jornada de Economía Crítica. Instituto Complutense de Estudios Internacionales. Recuperado de: http:// pendientedemigracion.ucm.es/info/ec/jec13/Ponencias/economia\%20 mundial/Financiarizacion\%20acumulacion\%20de\%20capital\%20y\%20 ajuste\%20salarial.pdf.

os Astarita, R. (2009). El capitalismo roto: anatomía de la crisis económica. Madrid: La linterna sorda.

os Astarita, R. (2010). Financiarización y rentabilidad financiera. [Mensaje en un blog]. Recuperado de: http://rolandoastarita.wordpress. com/2010/08/02/financiarizacion-y-rentabilidad-financiera-2/\#more-189

os Carney, B. (18 de octubre de 2008). Bernanke Is Fighting the Last War. The wall street journal. Recuperado de: http://online.wsj.com/article/ SB122428279231046053.html

os Chirinos, C. (30 de Diciembre de 2012). Washington paralizado al borde del abismo fiscal. BBC Mundo. Recuperado de: http://www.bbc.co.uk/ mundo/noticias/2012/12/121230_eeuu_washington_paralisis_abismo_ fiscal_cch.shtml

os Comisión Europea. (2008). Un plan europeo de recuperación económica. Comunicación de la Comisión al Consejo Europeo. Recuperado de: http://eur-lex.europa.eu/LexUriServ/LexUriServ. do?uri=COM:2008:0800:FIN:es:PDF

ç Duménil, G., \& Lévy, D. (2011). The crisis of neoliberalism. Cambridge, Mass.: Harvard University Press.

os Durán, T., Hernández, R., Merino V. y Reyes Y. (2010). Las políticas de ajuste estructural en El Salvador: Impacto sobre la inversión y distribución (1999-2010). (Tesis de licenciatura). Universidad Centroamericana "José Simeón Cañas" Recuperada de: http://www.uca.edu.sv/deptos/ economia/media/archivo/c7e45c_laspoliticasdeajusteestructuralenelsalvadorimpactosobrelainversionydistribucion(199.pdf

os Foster, J. B. (2010). The Financialization of Accumulation. Monthly Review, 62 (5). Recuperado de: http://monthlyreview.org/2010/10/01/ the-financialization-of-accumulation. 
os Friedman, M. (1979). Moneda y Desarrollo Económico. Barcelona: El Ateneo.

o3 Gill, L. (2002). Fundamentos y límites del capitalismo, Madrid:Trotta.

os Girón, A. y Chapoy, A. (2009). Financiarización y titulización: un momento Minsky. Economiaunam 6 (16). Recuperado de: http://www. ejournal.unam.mx/ecu/ecunam16/ECU001600603.pdf

os Guerrero, D. (2009). La crisis actual: de la geopolítica a la dinámica del sistema capitalista. kaosenlared.net Recuperado de: http://old.kaosenlared.net/noticia/crisis-actual-geopolitica-dinamica-sistema-capitalista

os Herndon, T., Ash, M. y Pollin, R. (2013). Does high Public Debt Consistently Stifle Economic Growth? A Critique of Reinhart and Rogoff. Political Economy Research Institute. Abril 2013 (322). Recuperado de:.http://www.peri.umass.edu/fileadmin/pdf/working_papers/working_ papers_301-350/WP322.pdf

os Keynes, J. M. (1965). Teoría general de la ocupación, el interés y el dinero. México, D.F.:Fondo de Cultura Económica.

os Kliman, A. (2011). The Failure of Capitalist Production: Underlying Causes of the Great Recession. Londres: Pluto Press.

os Kurata, P. (2009). Dos destacados economistas debaten los pros y los contras de la reglamentación. Sitio web de Oficina de Programas de Información Internacional del Departamento de Estado de Estados Unidos. Recuperado de: http://iipdigital.usembassy.gov/st/spanish/article /2009/05/20090519100831 emanym0.2165796.html\#axzz2R8m3SM4H

os Krugman, P. (2012). A Manifiesto for Economic Sense. The New York Times The Opinion Pages: The Conscience of a Liberal. Recuperado de: http://www.manifestoforeconomicsense.org/A-MANIFESTO-FORECONOMIC-SENSE.pdf [Accesado: en abril 2013].

os Kregel, J. (2007). The natural instability of financial markets. Levy Economics Institute of Bard College. Documento de trabajo No.523. Recuperado de: http://www.levyinstitute.org/pubs/wp_523.pdf

os Lavoie, M. (2005), La economia postkeynesiana, un antídoto del pensamiento único, Barcelona: Icaria.

os Martin, L. (30 de marzo de 2012). "Cualquier respuesta que no sea «austeridad» es una ilusión» —Robert Lucas. Truman factor. Recuperado de: http://trumanfactor.com/2012/entrevista-robert-lucas-8467.html

os Marx, K. (1973). El Capital. Tomo III. (P. Scaron, Trad.) México D.F.: Siglo $\mathrm{XXI}$. 
os Marx, K. (2001). Prólogo a la Contribución a la Crítica de la Economía Política (1859). Marxists Internet Archive. Recuperado de: http://www. marxists.org/espanol/m-e/1850s/criteconpol.htm

os Medialdea, B. (2009). Subdesarrollo, capital extranjero y financiarización. La trampa financiera de la economía brasileña. (Tesis doctoral). Universidad Complutense de Madrid.

os Meltzer, A. (2009). Regulatory Reform and the Federal Reserve. Truman Factor Recuperado de: http://trumanfactor.com/wp-content/ uploads/2012/03/meltzertestimony.pdf

os Montoya, A. (1998). Economía Crítica. San Salvador: Editores Críticos.

os Reinhart y Rogoff (2010). Growth in a time of debt. National Bureau Of Economic Research. Recuperado de: http://www.nber.org/papers/ w15639.pdf?new_window $=1$

os Roberts, M. (2009). The great recession. Profit cycles, economic crisis. A Marxist view. Recuperado de: http://archive.org/details/TheGreatRecession.ProfitCyclesEconomicCrisisAMarxistView

os Roberts, M. (2012). A Manifiesto for Socialist Sense. [Mensaje en un blog] Recuperado de: HYPERLINK "http://thenextrecession.wordpress. com/2012/07/03/a-manifesto-for-socialist-sense/" http://thenextrecession. wordpress.com/2012/07/03/a-manifesto-for-socialist-sense/

os Schwartz, A. (2008). Origins of the Financial Market Crisis of 2008. Cato Journal 29 (1) Recuperado de: http://www.cato.org/sites/cato.org/files/ serials/files/cato-journal/2009/1/cj29n1-2.pdf

os Schweickart, D. (1997). Más allá del capitalismo. Santander: Sal Terrae.

os Shaikh, A. (2010). The first great depression of the $21^{\text {st }}$ century. Forthcoming Fall. 2010, pp. 44-63.

os Tapia, J. (2010). Causas de las crisis: burbujas, machismo y otras explicaciones económicas de nuestra penuria. Sin Permiso. Abril 2010. Recuperado de: http://sitemaker.umich.edu/tapia_granados/files/ causas_de_las_crisis_-_sp_abril_2010.pdf

os Taylor, J. (2009). Sin rumbo: de como las acciones e intervenciones publicas causaron, prolongaron y empeoraron la crisis financiera. Vol 31. Madrid: Gota a gota.

os Wray, R. L. (2007). Lessons from the Subprime Meltdown. Levy Economics Institute of Bard College. Documento de trabajo No. 522 Recuperado de: http://www.levyinstitute.org/pubs/wp_522.pdf 


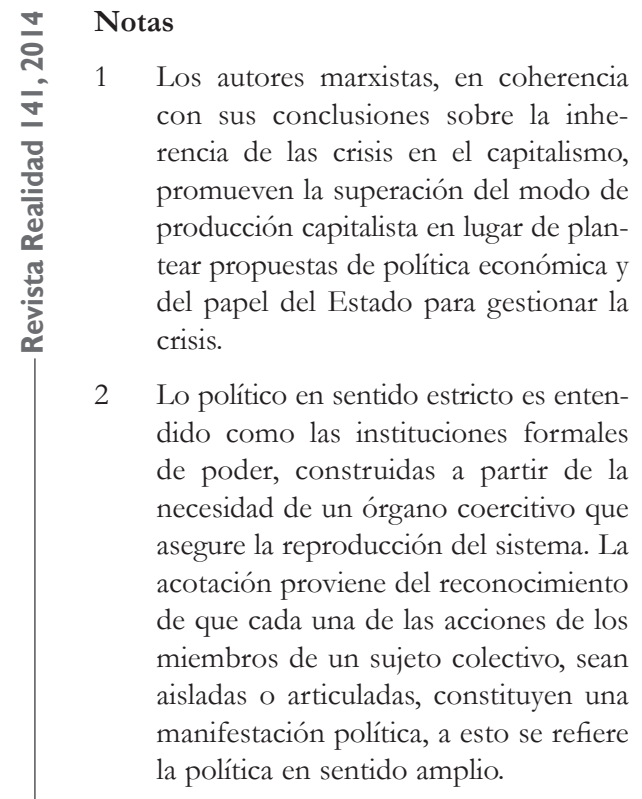

3 Como ejemplo de esto, la consigna de estos grupos en cuanto a la desigual distribución del ingreso: "Somos el $99 \% "$

4 Según las Encuestas de Hogares de Propósitos Múltiples (EHPM) de 2010 y 2011, la alícuota de remesas destinada al consumo era del $91.6 \%$ y $94.05 \%$, respectivamente. Las importaciones, con respecto al consumo, representan el $46.33 \%, 50.03 \%$ y $53.29 \%$, para 2009, 2010 y 2011, respectivamente.

5 La dinámica de la tasa de ganancia para el período 1960-2008 presenta una tendencia decreciente, según los resultados de Durán, Hernández, Merino y Reyes (2010). 